\title{
PENGARUH PENGALAMAN PASIEN TERHADAP LOYALITAS PASIEN DI RUMAH SAKIT UMUM DAERAH HAJI MAKASSAR
}

\section{THE IMPACT OF PATIENT EXPERIENCE TO PATIENT LOYALTY IN HAJI, MAKASSAR REGIONAL PUBLIC HOSPITAL}

\author{
Uleng Utari, Fridawaty Rivai, Nurshanty S Andi Sapada, \\ Bagian Administrasi Rumah Sakit, Fakultas Kesehatan Masyarakat, Universitas Hasanuddin,
}

\begin{abstract}
Alamat Korespondensi: Uleng Utari, drg, Fakultas Kesehatan Masyarakat, Universitas Hasanuddin Makassar, 90245, HP: 08114123811,Email: ulengutari@gmail.com

Abstrak

Pengukuran kualitas pelayanan menggunakan indikator pengalaman pasien masih jarang di lakukan di Indonesia.Penelitian ini bertujuan untuk melihat pengaruh Pengalaman Pasien terhadap Loyalitas Pasien di RSUD Haji Makassar. Penelitian ini merupakan jenis penelitian kuantitatif. Rancangan yang digunakan adalah studi observasional dengan desain cross sectional study. Pengumpulan data dilakukan melalui wawancara menggunakan kuesioner. Responden penelitian adalah pasien di instalasi rawat inap RSUD Haji Makassar dengan jumlah sampel sebanyak 152 orang. Analisis data menggunakan regresi linear sederhana untuk melihat pengaruh variabel independen terhadap variabel dependen dan menggunakan uji regresi linear berganda untuk melihat variabel independen yang paling berpengaruh terhadap variabel dependen. Hasil penelitian menunjukkan bahwa ada pengaruh signifikan antara pengalaman pasien terhadap loyalitas pasien pada instalasi rawat inap RSUD Haji Makassar dengan ( $p$ value $(0.001)<0.05$ ). Nilai $\mathrm{p}$ value bertuut-turut untuk dimensi komunikasi perawat, dimensi komunikasi dokter, dimensi responsif, dimensi kenyamanan fisik, dimensi kontrol terhadap nyeri, dimensi komunikasi tentang obat dan dimensi informasi kepulangan yaitu 0,$014 ; 0,011 ; 0,003 ; 0,147$; 0,098; 0,001; dan 0,001. Dari hasil nilai Coeffisien Beta ternyata dimensi komunikasi tentang obat yang mempunyai nilai paling besar, yaitu 0,158 . Disimpulkan bahwa bahwa pengalaman pasien berpengaruh terhadap loyalitas pasien dan dimensi pengalaman pasien yang berpengaruh terhadap loyalitas pasien yaitu dimensi komunikasi perawat, komunikasi dokter, responsif, komunikasi tentang obat dan informasi kepulangan, dan yang berpengaruh paling besar yaitu dimensi komunikasi tentang obat.
\end{abstract}

Kata kunci : pengalaman pasien, loyalitas pasien

\begin{abstract}
Measuring service quality using patient experience indicators is still rarely done in Indonesia. This study aims to see the effect of Patient Experience on Patient Loyalty In Haji Makassar Hospital. This research is a kind of quantitative research. The design used was observational study with cross sectional study design. Data collection was done through interview using questionnaire. The respondents were patients at the inpatient installation of Haji Makassar Hospital with a total sample of 152 people. The data analysis using simple linear regression to see the effect of independent variable to dependent variable and using multiple linear regression test to see the independent variable that most influence to the dependent variable. The results showed that there was a significant influence between patient experience on patient loyalty on inpatient installation of Haji Makassar Hospital with ( $p$ value $(0.001)<0.05)$. The value of $p$ value is consecutively for nurse communication dimension, physician communication dimension, responsive dimension, physical comfort dimension, control dimension to pain, drug communication dimension and information dimension of return of 0,014; $0.011 ; 0.003$; 0.147; 0.098; 0.001; and 0.001. From the results of Coeffisien Beta value turns out the communication dimension of the drug that has the greatest value, that is 0.158. It was concluded that the dimensions of patient experience that influence the loyalty of the patient are nurse communication dimension, physician communication, responsive, drug communication and return information, and the most influential is the communication dimension of drug.
\end{abstract}

Keywords: patient experience, patient loyalty 


\section{PENDAHULUAN}

Pelanggan yang puas merupakan aset penting bagi penyedia layanan kesehatan karena mereka berniat untuk menggunakan kembali layanan ini dan merekomendasikannya kepada keluarga dan teman mereka (Elleuch, 2008). Data kepuasan pasien di RSUD Haji Makassar pada tahun 2015 adalah 71, 28\%. Data ini menunjukkan tingkat kepuasan pasien yang belum memenuhi standar Kepmenkes No 129 tahun 2008 yang mensyaratkan kepuasan pasien pada instalasi Rawat Inap adalah $\geq 90 \%$.

Survei kepuasan pasien merupakan metode umum yang paling banyak digunakan dalam pengukuran kualitas pelayanan kesehatan (Coulter, 2009). Menurut Donabedian (2013), kepuasan dapat dianggap sebagai pertimbangan dan keputusan penilaian pasien terhadap efektivitas pelayanan. Namun, Cleary (1991) menyatakan bahwa survei kepuasan pasien memiliki keterbatasan karena bersifat subjektif dan sulit untuk ditafsirkan karena merupakan fungsi yang kompleks dalam menilai harapan yang mungkin sangat bervariasi antara pasien dengan perawatan yang sama.

Berbeda dengan pengukuran kepuasan pasien yang meminta pasien untuk mengevaluasi apa yang terjadi, pengukuran pengalaman pasien ingin menggali apa yang sebenarnya terjadi (Jenkinson, C et al, 2002). Oleh karena itu, beberapa peneliti mulai menggunakan tools pengalaman pasien untuk mengindikasikan masalah kualitas pelayanan.

Pengukuran kualitas pelayanan melalui pengalaman pasien sebagai indikator masih jarang di lakukan di Indonesia. Tapi di beberapa negara berkembang dimana perawatan berfokus pada pasien,ukuran kualitas pelayanan tidak hanya pada puas tidaknya pasien tapi lebih kepada bagaimana pengalaman mereka selama mendapatkan perawatan di rumah sakit. Melalui survei terhadap pengalaman pasien, maka peningkatan kualitas pelayanan rumah sakit dapat lebih terfokus kepada hal-hal yang benar-benar perlu untuk dilakukan perbaikan.

Pengalaman pelanggan memiliki pengaruh yang signifikan terhadap pembentukan dan pemeliharaan loyalitas pelanggan (Mascarenhas et al., 2006; Pullman \& Gross, 2004). Pengalaman akan kualitas yang baik dapat menciptakan loyalitas dan cenderung akan berbagi pengalaman tersebut kepada orang lain (Wolf, 2013).

Berdasarkan uraian di atas, peneliti ingin mendalami pengaruh antara variabel pengalaman pasien terhadap loyalitas pasien. Peneliti meyakini bahwa dengan melakukan perbaikan pada dimensi pengalaman pasien, dapat berpengaruh besar terhadap loyalitas pelanggan, sehingga dapat meningkatkan jumlah kunjungan rawat inap ke rumah sakit.

\section{BAHAN DAN METODE \\ Lokasi dan Rancangan penelitian}

Penelitian ini dilakukan di Rumah Sakit Umum Daerah Haji Makassar. Jenis penelitian yang digunakan adalah survey analitik, dengan rancangan cross sectional study.

\section{Populasi dan sampel}

Populasi penelitian ini adalah pasien rawat inap yang menggunakan jasa pelayanan kesehatan di RSUD Haji Makassar pada saat penelitian. Rata-rata jumlah pasien per bulan pada tahun 2017 yaitu 884 orang. Penarikan sampel dalam penelitian ini menggunakan metode purposive sampling yaitu teknik penentuan sampel dengan pertimbangan tertentu. Sampel diambil pada masing-masing kelas perawatan dilakukan secara proportional stratified random sampling. Berdasarkan hasil perhitungan, didapatkan besar sampel sebanyak 152 responden.

\section{Metode Pengumpulan Data}

Pengumpulan data primer diperoleh melalui teknik pengumpulan data dengan menggunakan kuesioner, yang berisi pertanyaan karakteristik responden (umur, jenis kelamin, tingkat pendidikan, pekerjaan, penghasilan, lokasi tempat 
tinggal, jarak tempat tinggal ke rumah sakit, dan sumber pembiayaan masuk rumah sakit), serta pertanyaan pengalaman pasien dan loyalitas pasien. Sedangkan data sekunder dalam penelitian ini diperoleh dari Analisis Data

Data yang terkumpul diolah dengan menggunakan SPSS. Analisis univariat dilakukan untuk mendapatkan gambaran umum karakteristik responden, pengalaman pasien dan dimensinya serta loyalitas pasien yang dianalisis menggunakan tabel distribusi frekuensi. Sedangkan untuk melihat keterkaitan antar variabel independen dan variabel dependen, digunakan uji statistik regresi linear sederhana. Dan untuk menentukan dimensi pengalaman pasien mana yang paling dominan berpengaruh terhadap loyalitas pasien, dilanjutkan dengan analisis regresi linear berganda.

\section{HASIL}

\section{Karakteristik sampel}

Sebagian besar responden yakni 25\% (38 responden) berada dalam kelompok umur 25-34 Tahun dan 35-44 Tahun. Bila dilihat dari jenis kelamin, jumlah laki-laki dan perempuan tidak jauh berbeda yaitu laki-laki sebesar 40,1\% (61 responden) sedangkan perempuan sebesar 59,9\% (91 responden). Berdasarkan jenis pekerjaan terbanyak yaitu sebagai tidak bekerja/ ibu rumah tangga sebanyak 35,5\% (54 responden) dengan penghasilan responden sebagian besar yaitu tidak mempunyai penghasilan sebesar 40,8\% (62 responden). Sedangkan berdasarkan jenis pembiayaan sebagian besar adalah BPJS PBI (Penerima Bantuan Iuran) yaitu sebesar $53,3 \%$ (81 responden) dengan tingkat pendidikan responden terbanyak yaitu SMA/SMK /SLTA sebesar 38,8\% (59 responden). Berdasarkan lokasi tempat tinggal, responden sebagian besar bertempat tinggal di dalam kota Makassar sebesar 78,9\% (120 responden) dan sebagian besar jarak antara tempat tinggal ke RS yaitu kurang dari 5KM sebanyak $59,2 \%$ (90 responden). laporan dan dokumen rumah sakit, yang meliputi profil rumah sakit, jumlah kunjungan, survey kepuasan pasien serta data lain yang terkait dengan penelitian ini.

\section{Analisis Univariat}

Tabel 1 menunjukkan bahwa hampir semua responden yakni 96,1\% (146 responden), berada dalam kategori pengalaman pasien yang tergolong baik. Sehingga dapat disimpulkan bahwa pengalaman pasien tergolong baik di Instalasi Rawat Inap RSUD Haji Makassar. Pada tabel 2, hampir sebagian besar responden menilai dimensi yang digunakan untuk menilai kualitas pengalaman di rumah sakit memiliki penilaian yang baik. Ditinjau dari dimensi komunikasi perawat, hampir semua responden yakni 140 responden $(92,1 \%)$ memiliki penilaian yang baik. Dimensi komunikasi dokter juga memiliki penilaian yang baik oleh hampir seluruh responden yakni 142 responden $(93,4 \%)$.

Dari dimensi responsif, terdapat 115 responden $(75,7 \%)$ yang memiliki penilaian baik. Begitu juga dengan dimensi kenyamanan fisik, dimana terdapat 124 responden $(81,6 \%)$ menilai baik. Dua dimensi yang terakhir yakni dimensi komunikasi tentang obat, terdapat 116 responden $(76,3 \%)$ dan 127 responden $(83,6 \%)$ yang menilai dimensi informasi kepulangan dengan kategori baik.

Tabel 3 menunjukkan bahwa hampir semua responden yakni 92,1\% (144 responden), berada dalam kategori pasien yang tergolong loyal. Sehingga dapat disimpulkan bahwa pasien tergolong loyal di Instalasi Rawat Inap RSUD Haji Makassar.

\section{Analisis Bivariat}

Pada uji bivariat menunjukkan bahwa ada pengaruh signifikan antara pengalaman pasien terhadap loyalitas pasien pada instalasi rawat inap RSUD Haji Makassar dengan ( $p$ value $(0.001)<0.05)$. Sedangkan untuk pengaruh dimensi pengalaman pasien terhadap loyalitas pasien didapatkan nilai $\mathrm{p}$ value berturut- 
turut untuk dimensi komunikasi perawat, dimensi komunikasi dokter, dimensi responsif, dimensi kenyamanan fisik, dimensi kontrol terhadap nyeri, dimensi komunikasi tentang obat dan dimensi informasi kepulangan yaitu 0,$014 ; 0,011$; 0,$003 ; 0,147 ; 0,098 ; 0,001$; dan 0,001 .

Tabel 1. Distribusi frekuensi responden berdasarkan variabel pengalaman pasien di Instalasi Rawat Inap RSUD Haji Makassar tahun 2017

\begin{tabular}{llcc}
\hline & Variabel Penelitian & Frekuensi (n) & Persentasi (\%) \\
\hline $1 \quad$ Pengalaman Pasien & 146 & \\
a. Baik & 6 & 96,1 \\
& b. Kurang Baik & 3,9 \\
\hline
\end{tabular}

Sumber : Data Primer, 2017

Tabel 2. Distribusi frekuensi responden berdasarkan dimensi pengalaman pasien instalasi rawat inap RSUD Haji Makassar tahun 2017

\begin{tabular}{|c|c|c|c|}
\hline No & Dimensi Pengalaman Pasien & Frekuensi (n) & Persentasi (\%) \\
\hline 1 & $\begin{array}{l}\text { Komunikasi Perawat } \\
\text { a. Baik } \\
\text { b. Kurang Baik }\end{array}$ & $\begin{array}{c}140 \\
12 \\
\end{array}$ & $\begin{array}{c}92,1 \\
7,9 \\
\end{array}$ \\
\hline 2 & $\begin{array}{l}\text { Komunikasi Dokter } \\
\text { a. Baik } \\
\text { b. Kurang Baik }\end{array}$ & $\begin{array}{c}142 \\
10 \\
\end{array}$ & $\begin{array}{c}93,4 \\
6,6\end{array}$ \\
\hline 3 & $\begin{array}{l}\text { Responsif } \\
\text { a. Baik } \\
\text { b. Kurang Baik }\end{array}$ & $\begin{array}{c}115 \\
37\end{array}$ & $\begin{array}{l}75,7 \\
24,3\end{array}$ \\
\hline 4 & $\begin{array}{l}\text { Kenyamanan Fisik } \\
\text { a. Baik } \\
\text { b. Kurang Baik }\end{array}$ & $\begin{array}{c}124 \\
28 \\
\end{array}$ & $\begin{array}{l}81,6 \\
18,4\end{array}$ \\
\hline 5 & $\begin{array}{l}\text { Kontrol rasa nyeri } \\
\text { a. Baik } \\
\text { b. Kurang Baik }\end{array}$ & $\begin{array}{c}148 \\
4\end{array}$ & $\begin{array}{c}97,4 \\
2,6\end{array}$ \\
\hline 6 & $\begin{array}{l}\text { Komunikasi tentang obat } \\
\text { a. Baik } \\
\text { b. Kurang Baik }\end{array}$ & $\begin{array}{c}116 \\
36\end{array}$ & $\begin{array}{l}76,3 \\
23,7 \\
\end{array}$ \\
\hline 7. & $\begin{array}{l}\text { Informasi Kepulangan } \\
\text { a. Baik } \\
\text { b. Kurang Baik }\end{array}$ & $\begin{array}{c}127 \\
25\end{array}$ & $\begin{array}{l}83,6 \\
16,4\end{array}$ \\
\hline & Total & 152 & 100 \\
\hline
\end{tabular}

Sumber : Data Primer, 2017

\section{Analisis Multivariat}

Hasil penelitian pada Tabel 4 menunjukkan bahwa dimensi pengalaman pasien yang paling dominan berpengaruh terhadap variabel loyalitas pasien di RSUD Haji Makassar adalah dimensi komunikasi tentang obat (Coeffisien Beta= 0,158). 
Tabel 3. Distribusi Frekuensi Responden Berdasarkan Variabel Loyalitas Pasien Instalasi Rawat Inap RSUD Haji Makassar Tahun 2017

No Variabel Penelitian $\quad$ Frekuensi (n) Persentasi (\%)

1 Loyalitas
a. Loyal
144
92,1
b. Tidak Loyal
8
7,9

Sumber : Data Primer, 2017

Tabel 4. Hasil Perhitungan Nilai Coefficient Variabel Pengalaman Pasien terhadap Loyalitas Pasien

\begin{tabular}{llrrr}
\hline \multicolumn{1}{c}{ Model } & \multicolumn{2}{c}{$\begin{array}{c}\text { Standardized } \\
\text { Coefficients }\end{array}$} & t & Sig. \\
\cline { 3 - 4 } & \multicolumn{2}{c}{ Beta } & & \\
\hline \multirow{1}{*}{ (Constant) } & & 3.415 & .001 \\
\cline { 2 - 4 } & KOMUNIKASI PERAWAT & .043 & .460 & .646 \\
\cline { 2 - 4 } & KOMUNIKASI DOKTER & .084 & .898 & .371 \\
\hline RESPONSIF & .099 & 1.065 & .289 \\
\hline KENYAMANAN FISIK & .005 & .061 & .951 \\
\hline KONTROL RASA NYERI & .058 & .711 & .478 \\
\hline KOMUNIIKASI TTG OBAT & .158 & 1.679 & .095 \\
\hline INFORMASI KEPULANGAN & .086 & .859 & .392 \\
\hline
\end{tabular}

Sumber : Data Primer, 2017

\section{PEMBAHASAN}

Dalam penelitian ini terlihat bahwa ada beberapa variabel yang secara signifikan mempengaruhi loyalitas pasien yaitu pengalaman pasien, dimensi komunikasi perawat, komunikasi dokter, responsif, kenyamanan fisik, komunikasi tentang obat dan informasi kepulangan.

Hasil yang diperoleh ini sejalan dengan penelitian yang dilakukan oleh Tabib J at al (2012), Gee R et al (2008), dan Olorunniwo $F$ et al (2006) yang menyatakan bahwa pengalaman pasien dalam hal layanan di rumah sakit memiliki dampak yang kuat terhadap keinginan pasien untuk kembali dan merekomendasikannya kepada orang lain. Dimensi pengalaman pasien berpengaruh terhadap loyalitas pasien. Dari hasil uji, dimensi komunikasi perawat, komunikasi dokter, responsif, kenyamanan fisik, komunikasi tentang obat, dan Informasi pada saat pasien pulang yang memiliki pengaruh terhadap loyalitas pasien di Instalasi Rawat Inap RSUD Haji Makassar.
Menurut Akbar et al (2013), agar kebutuhan pasien terpenuhi, salah satu tindakan yang diharapkan adalah perawat dapat membina hubungan baik dengan pasien melalui teknik dan sikap komunikasi selama memberikan asuhan keperawatan kepada pasien dan dalam penelitian Suparyo (2015), terdapat hubungan yang positif antara kualitas komunikasi dokter- pasien dengan tingkat loyalitas pasien. Hal ini sesuai dengan pertanyaan terbuka yang diajukan peneliti bahwa sebagian besar responden menyatakan bahwa pelayanan yang baik dari perawat maupun dokter merupakan alasan terbesar mereka untuk kembali menggunakan layanan kesehatan di RSUD Haji Makassar.

Responsif merupakan salah satu dimensi dalam pengalaman pasien yang diteliti dalam penelitian ini dan didapatkan bahwa dimensi responsif berpengaruh terhadap loyalitas pasien. Hal ini sejalan dengan penelitian oleh Murharyati \& Oktariani (2014) yang menyatakan bahwa ada hubungan antara tingkat responsif 
dengan tingkat loyalitas pasien. Walaupun ada $40,1 \%$ yang menyatakan bahwa tidak pernah dibantu oleh perawat pada saat membutuhkan bantuan ke kamar mandi atau dibantu menggunakan pispot. Hal ini disebabkan tenaga perawat yang tidak sebanding dengan jumlah tempat tidur, maka yang didahulukan adalah pasien yang dalam kondisi darurat, atau yang tidak mempunyai pendamping.Dimensi pengalaman pasien lain yang ditemukan pengaruhnya terhadap loyalitas pasien, adalah komunikasi tentang obat dan informasi kepulangan. Berbeda dengan dimensi kontrol terhadap rasa nyeri dan kenyamanan fisik, dalam penelitian ini tidak ditemukan pengaruhnya terhadap loyalitas pasien.

Dari hasil uji multivariat, didapatkan pengalaman pasien berdasarkan dimensi komunikasi tentang obat yang paling besar pengaruhnya (dominan) terhadap loyalitas pasien.

Pemberian obat menjadi salah satu tugas perawat yang paling penting, dimana perawat adalah mata rantai terakhir dalam proses pemberian obat kepada pasien. Perawat yang bertanggung jawab bahwa obat itu diberikan dan memastikan bahwa obat itu benar diminum. Bila ada obat yang diberikan kepada pasien, hal itu harus menjadi bagian integral dari rencana keperawatan. Perawat yang paling tahu tentang kebutuhan dan respon pasien terhadap pengobatan. Misalnya, pasien yang sukar menelan, muntah atau tidak dapat minum obat tertentu (dalam bentuk kapsul). Faktor gangguan visual, pendengaran, intelektual atau motorik, yang mungkin menyebabkan pasien sukar makan obat, harus dipertimbangkan. Rencana perawatan harus mencakup rencana pemberian obat, bergantung pada hasil pengkajian, pengetahuan tentang kerja dan interaksi obat, efek samping, lama kerja, dan program dokter (Rifa, 2011)

Komunikasi atau penjelasan mengenai kegunaan, efek samping dan jadwal pengomsusian obat sangat berpengaruh pada tingkat kepatuhan pasien. Penerapan penjelasan mengenai manfaat obat sebagai salah satu bentuk komunikasi dalam praktek kefarmasian pada pasien dapat meningkatkan kepatuhan pasien dalam penggunaan obat karena pasien mendapatkan penjelasan mengenai manfaat penggunaan obat yang sesuai dengan aturan pakai yang sangat berpengaruh dalam meningkatkan kualitas hidup pasien.

\section{KESIMPULAN DAN SARAN}

Kami menyimpulkan bahwa pengalaman pasien berpengaruh terhadap loyalitas pasien dan dimensi pengalaman pasien yang berpengaruh terhadap loyalitas pasien yaitu dimensi komunikasi perawat, komunikasi dokter, responsif, komunikasi tentang obat dan informasi kepulangan. Adapun dua dimensi pengalaman pasien yang tidak ditemukan pengaruh adalah dimensi kenyamanan fisik dan kontol terhadap nyeri. Dari hasil uji multivariat, didapatkan dimensi pengalaman pasien yang berpengaruh paling besar yaitu dimensi komunikasi tentang obat. Oleh karena itu perlu adanya perhatian manajerial seperti penambahan tenaga apoteker di RSUD Haji Makassar agar tercipta kerjasama yang baik antara dokter, apoteker dan perawat sebagai ujung tombak pemberian obat kepada pasien.

\section{UCAPAN TERIMA KASIH}

Penulis mengucapkan terima kasih kepada para pembimbing untuk bimbingan dan motivasinya serta rekan seperjuangan yang senantiasa memberikan dukungan dalam penelitian ini. Terima kasih kepada perawat dan staf rumah sakit yang sudah bersedia membantu dalam penelitian ini. Dan semua pihak yang telah membantu hingga penelitian ini selesai dilaksanakan.

\section{DAFTAR PUSTAKA}

Akbar, A. P., Sidin, I., \& Pasinringi, S. A. (2013). Gambaran Kepuasan Pasien terhadap Pelaksanaan Komunikasi Terapeutik Perawat di Instalasi Rawat Inap RSUD Labuang Baji Makassar Tahun 2013. Manajemen Rumah Sakit Fakultas Kesehatan Masyarakat Universitas Hasanuddin, 1-11. 
Cleary, P. D. et al. (1991). Patients Evaluate Their Hospital Care: A National Survey by. Health Affairs. https://doi.org/10.1377/hlthaff.10.4.25 4

Coulter, A. (2009). The Point of Care Measures of patients 'experience in hospital: purpose, methods. The King's Fund, 1-32.

Elleuch, A. (2008). Patient satisfaction in Japan. International Journal of Health Care Quality Assurance, 21(7), 692705.

https://doi.org/10.1108/095268608109 10168

Gee, R., Coates, G., Nicholson, N.,( 2008). Understanding and Profitably Managing Customer Loyalty. Marketing and Intelligence \& Planning. 26(4), pp. 359-374.

Jenkinson, C; Coulter, A; Bruster, S; Richards, N; Chandola, T. (2002). Patients' experiences and satisfaction with health care: results of a questionnaire study of specific aspects of care. Quality Saf Health Care, 11, 335-339.

Mascarenhas, O. A., Kesavan, R., Bernacchi, M., Mascarenhas, O. A., Kesavan, R., \& Bernacchi, M. (2006). Lasting customer loyalty: a total customer experience approach. Journal of Consumer Marketing, 23(7), 397-405. https://doi.org/10.1108/073637606107 12939
Murharyati, A., \& Oktariani, M. (2014). Hubungan antara responsiveness perawat dengan loyalitas pasien. Jurnal KesMaDaSka, 117-123.

Olorunniwo F, Hsu MK, Udo GJ.,(2006). Sevice Quality, Customer Satisfaction, and Behavioral Intentions in The Service Factory.,20(1):59-72

Pullman, M. E., \& Gross, M. A. (2004). Ability of Experience Design Elements to Elicit Emotions and Loyalty Behaviors. Decision Sciences, 35(3), 551-579.

Rifa, F. (2011). Integrasi Konsep Komunikasi dan Etika dalam Pemberian Obat. Retrieved from https://riff46.wordpress.com/

Suparyo, S. W. (2015). Hubungan Antara Kualitas Komunikasi Dokter-Pasien dan Tingkat Pendidikan Pasien dengan Loyalitas Pasien. Jurnal Interaksi Online. Retrieved from https://www.neliti.com/id/publications/ 188871/hubungan-antara-kualitaskomunikasi-dokter-pasien-dan-tingkatpendidikan-pasien

Tabibi J, Ghohari M, Bighdeli M, Shahri S. (2012). The Relationship Between ServiceQuality and Patient's Loyalty in Tehran Public and Privat Hospital.3(6):194-203

Wolf, J. A. (2013). A report on the Beryl Institute benchmarking study the state of patient experience in American Hospitals 2013. The Beryl Institute. 